\title{
Enhancement of $\gamma$-Aminobutyric Acid-activated Chloride Channel Currents by Lanthanides in Rat Dorsal Root Ganglion Neurons
}

\author{
Jenny Yan Ma and Toshio Narahashi \\ Department of Pharmacology, Northwestern University Medical School, Chicago, Illinois 60611
}

\begin{abstract}
Lanthanum was previously reported to potentiate the GABAinduced chloride currents reversibly by acting at a distinct site on the GABA receptor-channel complex (Ma and Narahashi, 1993). We now report that all other lanthanides tested enhanced the GABA responses with greater efficiencies and produced inward currents by themselves. The rank order of efficacies of lanthanides to potentiate the GABA responses and to generate currents correlated inversely with the hydrated ionic radii of these ions. The GABA-induced currents were recorded from the rat dorsal root ganglion neurons in primary culture by the whole-cell patch-clamp technique. Lanthanides at $1 \mathrm{~mm}$ reversibly potentiated the GABA responses (times of control): lutetium $\left(\mathrm{Lu}^{3+}\right) \mathrm{C} 2.4 \pm$ $0.1>$ erbium $\left(\mathrm{Er}^{3+}\right) 11.4 \pm 0.2>$ terbium $\left(\mathrm{Tb}^{3+}\right) \mathbf{9} .3 \pm 0.5$ $>$ europium $\left(\mathrm{Eu}^{3+}\right) \mathbf{5} .4 \pm 0.4>$ neodymium $\left(\mathrm{Nd}^{3+}\right) 4.1 \pm 0.2$ $>$ cerium $\left(\mathrm{Ce}^{3+}\right) 3.3 \pm 0.2>$ lanthanum $\left(\mathrm{La}^{3+}\right) 2.4 \pm 0.2(n$ $=10)$. The enhancing effect of $\mathrm{Tb}^{3+}$ was dose dependent, with an $E C_{50} 356 \pm 12 \mu \mathrm{M}(n=10)$, and weakly voltage dependent, increasing with hyperpolarization. The amplitudes of currents induced by various lanthanides $(1 \mathrm{mM})$ were (percentage of $10 \mu \mathrm{M}$ GABA-induced current) $\mathrm{Lu}^{3+} 101$ $\pm 8>\mathrm{Er}^{3+} 57 \pm 8>\mathrm{Tb}^{3+} 33 \pm 3>\mathrm{Eu}^{3+} 20 \pm 2>\mathrm{Nd}^{3+} 14$ $\pm 2 \approx \mathrm{Ce}^{3+} 13 \pm 0.6>\mathrm{La}^{3+} 10 \pm 0.2(n=4) . \mathrm{Tb}^{3+}$ reversibly induced currents in a dose-dependent manner with an $\mathrm{EC}_{50}$ of $863 \pm 0 \mu \mathrm{M}(n=5)$. The Tb ${ }^{3+}$-induced currents, which were not voltage dependent, were reversed in polarity at the chloride equilibrium potential. Both pentobarbital $(100 \mu \mathrm{M})$ and chlordiazepoxide $(50 \mu \mathrm{M})$ potentiated both GABA- and $\mathrm{Tb}^{3+-}$ induced currents equally. The GABA receptor-channel antagonists bicuculline $(10 \mu \mathrm{M})$, picrotoxin $(10 \mu \mathrm{M})$, penicillin $(500 \mu \mathrm{M})$, and $\mathrm{Zn}^{2+}(20$ and $100 \mu \mathrm{M})$ all suppressed the $\mathrm{Tb}^{3+}$ induced current. We suggest that there is a distinct binding site on the GABA receptor-channel complex for the lanthanides and, at high concentrations, lanthanides may act on the GABA site or some other site to open the GABA-gated chloride channels.
\end{abstract}

[Key words: lanthanides, lanthanum, GABA receptor, chloride channel, terbium, dorsal root ganglion]

\footnotetext{
Received Feb. 1, 1993; May 3, 1993; May 20, 1993.

This work was supported in part by a grant from the National Institutes of Health (NS14144). We thank Mr. Jonathan Bloom for maintaining the computer system.

Correspondence should be addressed to Dr. Toshio Narahashi, Department of Pharmacology, Northwestern University Medical School, 303 East Chicago Avenue, Chicago, IL 60611

Copyright (C) 1993 Society for Neuroscience $0270-6474 / 93 / 134872-08 \$ 05.00 / 0$
}

Lanthanide ions, or rare-earth metals, comprise a series of 15 metals starting with lanthanum $\left(\mathrm{La}^{3+}\right.$, atomic number 57) and ending with lutetium $\left(\mathrm{Lu}^{3+}\right.$, atomic number 71). The effective ionic radii of lanthanides gradually contract from $\mathrm{La}^{3+}$ to $\mathrm{Lu}^{3+}$ as the atomic mass increases (Shannon, 1976). They are trivalent and similar in their chemical and biological properties to the alkaline earth elements. In the past, some lanthanide compounds were used in the treatment of tuberculosis, as anticoagulant agents for prevention of thrombosis, and as antinausea agents during early pregnancy (Haley, 1965; Venugopal and Luckey, 1978). More recently, lanthanides have been used in dentistry (Vardimon et al., 1991), for cancer treatment (Anghileri et al., 1987; Canada and Carpenter, 1991), as anti-inflammatory agents (Yamage and Evans, 1989), and as antivirus agents (Sedmak et al., 1986). The industrial application of lanthanides includes color TV, lasers, cameras, semiconductors, binoculars, and movies. With the increasing and continuing usage of lanthanides, it is necessary to obtain detailed information on the cellular pharmacology and toxicology of the lanthanides.

Lanthanides are known to interact with many cellular components such as nucleoproteins, amino acids, phospholipids, enzymes, and intermediary metabolites (Das et al., 1988). We previously reported that $\mathrm{La}^{3+}$ increased the GABA-induced chloride currents in rat dorsal root ganglion (DRG) neurons (Yan and Narahashi, 1991). However, the suppression effect of $\mathrm{La}^{3+}$ was found in rat dorsal horn neurons (Reichling and MacDermott, 1991). In order to elucidate the mechanism of action of lanthanum on the GABA receptor-channel complex, 7 of 15 lanthanides were employed in the present study including $\mathrm{Lu}^{3+}$, erbium $\left(\mathrm{Er}^{3+}\right.$, atomic number 68$)$, terbium $\left(\mathrm{Tb}^{3+}\right.$, atomic number 65 ), europium $\left(\mathrm{Eu}^{3+}\right.$, atomic number 63 ), neodymium $\left(\mathrm{Nd}^{3+}\right.$, atomic number 60$)$, cerium $\left(\mathrm{Ce}^{3+}\right.$, atomic number 58$)$, and $\mathrm{La}^{3+}$. All the lanthanides tested have been found to augment the GABA-induced chloride current, with the efficacy increasing with the atomic number. This positive modulation is in sharp contrast with negative modulation of the GABA receptor-channel complex caused by several divalent cations including $\mathrm{Zn}^{2+}$, $\mathrm{Cu}^{2+}$, and $\mathrm{Cd}^{2+}$ (Kaneko and Tachibana, 1986; Celentano et al., 1991; Smart, 1992; Ma and Narahashi, 1993).

\section{Materials and Methods}

Dorsal root ganglion neuron preparations. The dorsal root ganglia were dissected from the lumbosacral region of newborn Sprague-Dawley rats (1-2 d old) under methoxyflurane anesthesia, and were immediately placed into ice-cold, $\mathrm{Ca}^{2+} / \mathrm{Mg}^{2+}$-free phosphate-buffered saline solution (PBS) supplemented with $6 \mathrm{gm} /$ liter glucose. The ganglia were then digested in $\mathrm{Ca}^{2+} / \mathrm{Mg}^{2+}$ - free PBS containing $2.5 \mathrm{mg} / \mathrm{ml}$ trypsin (type XI, Sigma, St. Louis, MO) for $25 \mathrm{~min}$ at $37^{\circ} \mathrm{C}$. Digestion was terminated by removing the ganglia from the trypsin solution. Then the ganglia 
were washed with Dulbecco's modified Eagle's medium (DMEM) containing $0.1 \mathrm{mg} / \mathrm{ml}$ fetal bovine serum and $0.08 \mathrm{mg} / \mathrm{ml}$ gentamicin. The ganglia were dissociated by repeated trituration using a fire-polished Pasteur pipette in $2 \mathrm{ml}$ of DMEM. The dissociated cells were placed onto coverslips coated with poly-L-lysine $(0.1 \mathrm{mg} / \mathrm{ml}$; Sigma). Neurons were maintained in DMEM containing fetal bovine serum and gentamicin (see above), in a $90 \%$ air, $10 \% \mathrm{CO}_{2}$ atmosphere controlled at $36^{\circ} \mathrm{C}$. Neurons cultured for $1-5 \mathrm{~d}$ were used for experiments.

Current recording. The whole-cell variation of the patch-clamp technique was used to record ionic currents under voltage-clamp conditions (Hamill et al., 1981). Pipette electrodes were made from $1.5 \mathrm{~mm}$ (o.d.) borosilicate glass capillary tubes and had a resistance of about $3 \mathrm{M} \Omega$ when filled with standard internal solution. The transmembrane voltage was clamped at $-60 \mathrm{mV}$ and a $10 \mathrm{~min}$ period was allowed following rupture of the membrane to equilibrate the cell interior adequately with pipette solution. The membrane currents passing through the electrode were recorded with the Axopatch amplifier (Axopatch-1B, Axon Instruments, Burlingame, CA) and currents were stored in an LSI 11/73 computer (Digital Equipment, Pittsburgh, PA).

Solutions. The external and internal solutions for the whole-cell recording were designed to eliminate sodium and potassium currents. The standard internal solution contained (in $\mathrm{mM}$ ) $\mathrm{CsCl}, 140 ; \mathrm{CaCl}_{2}, 1$; ethyleneglycol bis-( $\beta$-aminoethylether)- $N, N, N^{\prime}, N^{\prime}$-tetraacetic acid (EGTA), 5 ; and $N$-2-hydroxyethylpiperazine- $N^{\prime}$-2-ethanesulfonic acid (HEPES), 10. $\mathrm{pH}$ was adjusted to 7.3 with Tris (hydroxymethyl) aminomethane (Tris base), and the osmolarity was $290 \mathrm{mOsm}$. The standard external solution contained (in mM) choline chloride, 136; $\mathrm{CaCl}_{2}, 2 ; \mathrm{MgCl}_{2}, 1$; and HEPES, 10. pH was adjusted to 7.3 with Tris base, and the osmolarity was raised to $290 \mathrm{mOsm}$ with sucrose. Test solutions were prepared on the day of experiments by diluting the following aqueous stock solutions with the standard external solution: 30 mM GABA, 100 mm lanthanides, $100 \mathrm{~mm} \mathrm{ZnCl}_{2}, 20 \mathrm{~mm}$ picrotoxin (PTX), $20 \mathrm{~mm}$ bicuculline, $100 \mathrm{~mm}$ penicillin, $20 \mathrm{~mm}$ pentobarbital (PB), and $20 \mathrm{~mm}$ chlordiazepoxide (CDPX). GABA and drugs other than lanthanides were purchased from Sigma Chemical Co. Lanthanides (all in chloride salts) were purchased from Aldrich Chemical Co. (Milwaukee, WI). The test solutions were applied through a U-shaped plastic tube described previously (Ma and Narahashi, 1993). Briefly, the recording chamber was continuously perfused with the normal external solution by a vacuum pump at a rate of $1-2 \mathrm{ml} / \mathrm{min}$ and the U-tube was continuously perfused with the test solution at a rate of $0.5 \mathrm{ml} / \mathrm{min}$. By interrupting the backflow with an electromagnetic valve operated by a computer, the ligand concentration of the solution bathing the cell could be changed within 100-200 msec (Fenwick et al., 1982).

Student's $t$ test was used in the statistical analysis of differences at the level of $P<0.05$. Results are presented as the mean \pm SEM. All experiments were carried out at a room temperature of $20-23^{\circ} \mathrm{C}$.

\section{Results}

Potentiation of GABA-induced chloride currents by lanthanides Rat DRG neurons were voltage clamped at $-60 \mathrm{mV}$ and challenged with GABA and other test drugs at 2-5 min intervals. Responses induced by $10 \mu \mathrm{M}$ GABA delivered by the U-tube method did not show appreciable rundown and stable currents were recorded for a period of $30-40 \mathrm{~min}$ after the rupture of the membrane. The concentration of GABA was selected on the basis of giving reproducible submaximal responses with minimal desensitization. With symmetrical chloride concentrations inside and outside, $10 \mu \mathrm{M}$ GABA evoked an inward chloride current (Fig. 1 $A$ ). Upon removal of the GABA from the bath, the current declined to the resting level within 1 sec. When 1 mM $\mathrm{Lu}^{3+}$ was applied together with $10 \mu \mathrm{M} \mathrm{GABA}$, the amplitude of GABA-induced current increased to 12.6-fold of control (Fig. $1 A$ ). This enhancing effect of $\mathrm{Lu}^{3+}$ occurred quickly and was completely reversible upon washing the cell with $\mathrm{Lu}^{3+}$-free solution. The similar results were obtained with six other lanthanides tested: $\mathrm{Er}^{3+}, \mathrm{Tb}^{3+}, \mathrm{Eu}^{3+}, \mathrm{Nd}^{3+}, \mathrm{Ce}^{3+}$, and $\mathrm{La}^{3+}$ (Fig. $1 B$ ). The degree of lanthanide potentiation of GABA responses varied between 2.4- and 12.4-fold of control at a concentration of $1 \mathrm{~mm}: \mathrm{Lu}^{3+} 12.4 \pm 0.1>\mathrm{Er}^{3+} 11.4 \pm 0.2>\mathrm{Tb}^{3+9} .3 \pm 0.5$

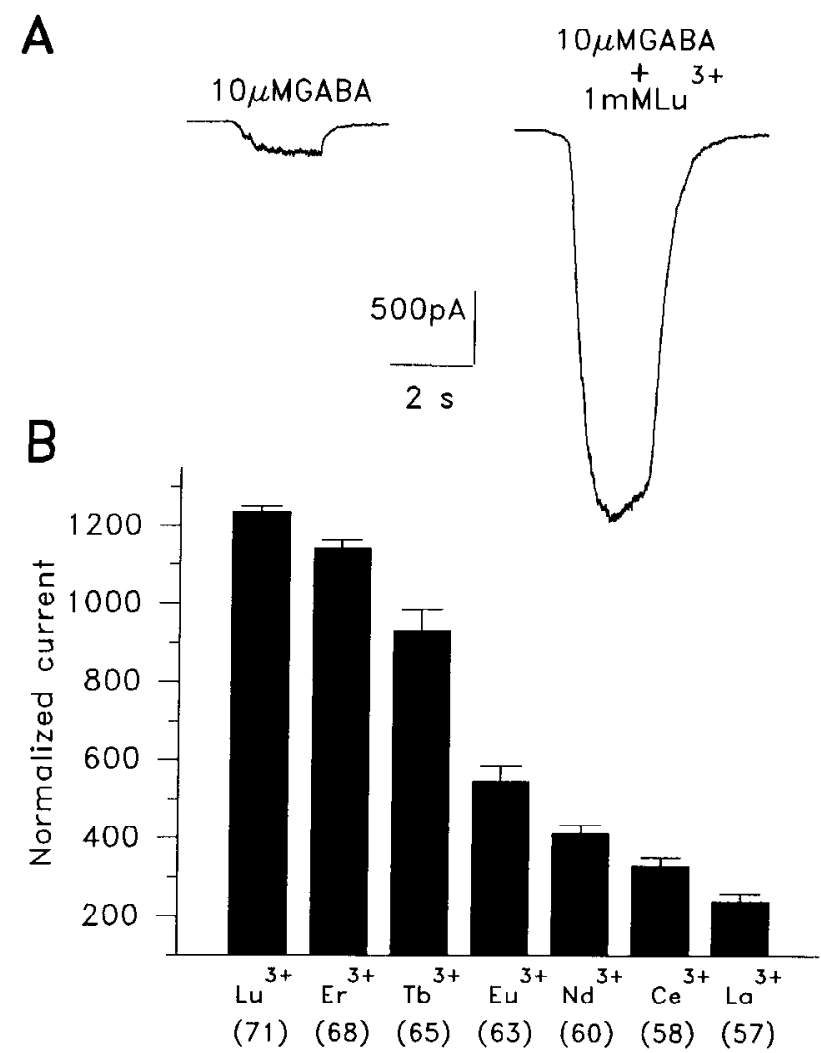

Figure 1. Enhancement of GABA-induced currents by lanthanides in cultured rat DRG neurons. $A$, GABA $(10 \mu \mathrm{M})$-induced inward chloride current was greatly enhanced (12.6 times of control) by adding $1 \mathrm{~mm}$ $\mathrm{Lu}^{3+}$. Holding potential, $-60 \mathrm{mV}$. The effect of $\mathrm{Lu}^{3+}$ was completely reversible. $B$, The chloride currents induced by $10 \mu \mathrm{M}$ GABA were potentiated by different lanthanides to different degrees. The ordinate represents the current amplitude with SEM $(n=10)$ normalized to 10 $\mu \mathrm{M}$ GABA-induced current. The numbers in parentheses are atomic numbers of lanthanides. The rank order of efficacies of lanthanide potentiation correlates with the atomic numbers of these ions.

$>\mathrm{Eu}^{3+} 5.4 \pm 0.4>\mathrm{Nd}^{3+} 4.1 \pm 0.2>\mathrm{Ce}^{3+} 3.3 \pm 0.2>\mathrm{La}^{3+}$ $2.4 \pm 0.2$ ( $n=10$ cells tested). This rank order of efficacy follows the atomic numbers of the lanthanides and correlates inversely with the hydrated ionic radii $(\AA)$ of these ions (values are given in ninefold coordination): $\mathrm{Lu}^{3+} 1.03<\mathrm{Er}^{3+} 1.06<\mathrm{Tb}^{3+} 1.10$ $<\mathrm{Eu}^{3+} 1.12<\mathrm{Nd}^{3+} 1.16<\mathrm{Ce}^{3+} 1.20<\mathrm{La}^{3+} 1.22$ (Shannon, 1976). $\mathrm{Tb}^{3+}$ was selected as a representative metal for further studics because it is one of the most frequently used lanthanides in several fields and produces remarkable potentiation of GABA responses.

The dose-response curve for $\mathrm{Tb}^{3+}$ enhancement of GABAinduced current was fitted by a curve using a four-parameter logistic function equation (Jandel Scientific, Corte Madera, CA):

$$
I=\left(I_{\max }-I_{\min }\right) /\left(1+\left(A / K_{d}\right)^{h}\right)+I_{\min },
$$

where $I$ is the amplitude of current, $I_{\max }$ is the maximum current, $I_{\min }$ is the minimum current, $K_{d}$ is the apparent dissociation constant that gives the half-maximal response, $A$ is the agonist or antagonist concentration, and $h$ is the Hill coefficient. Figure $2 A$ shows the increasing peak amplitude of the current induced by $10 \mu \mathrm{M}$ GABA with coapplication of the increasing concentration of $\mathrm{Tb}^{3+}$. The normalized current amplitudes are plotted as a function of the concentration of $\mathrm{Tb}^{3+}$ in Figure $2 B$. The 
A
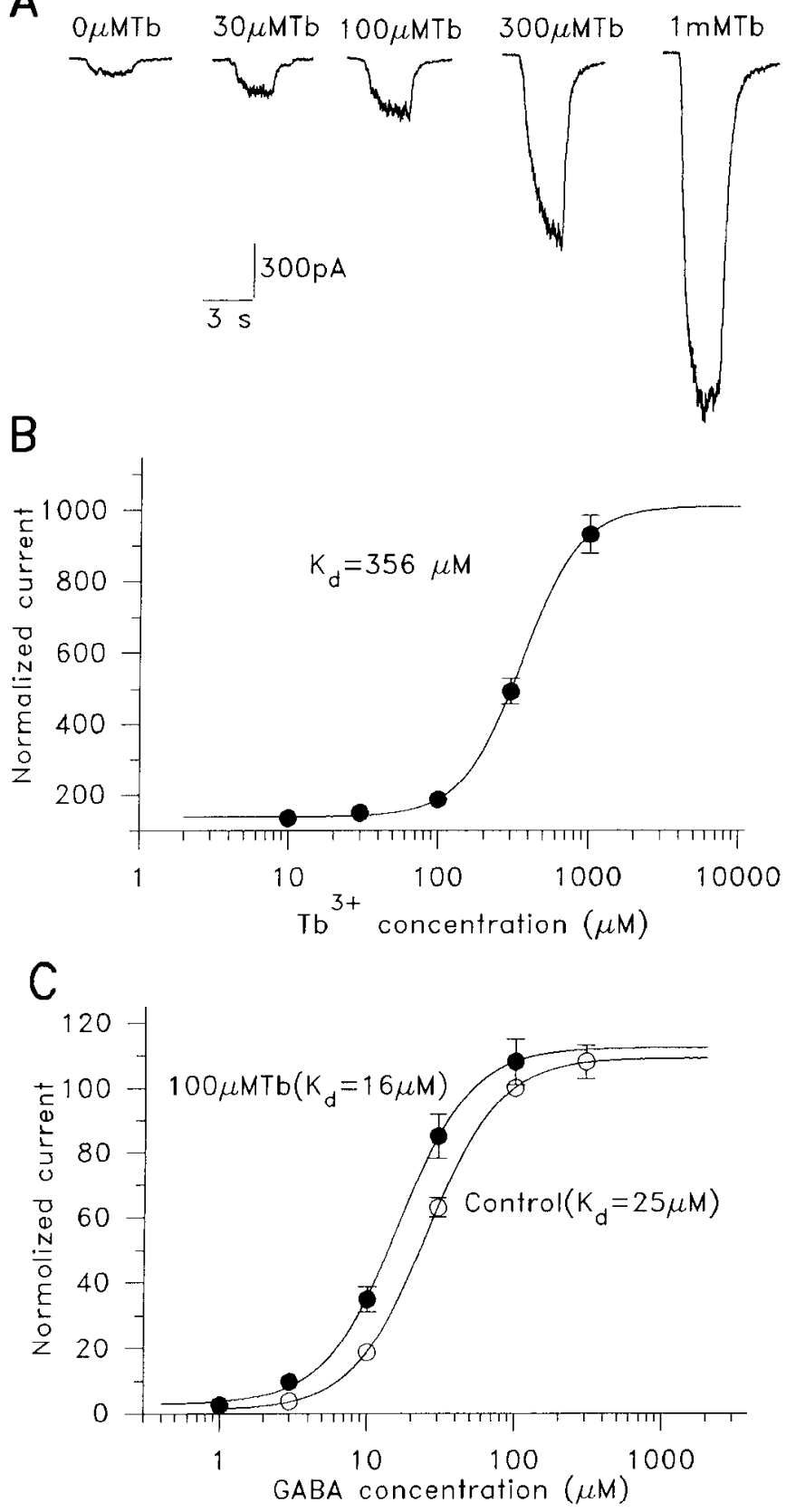

Figure 2. Potentiation of GABA responses by $\mathrm{Tb}^{3+} . A$, The responses to $10 \mu \mathrm{M}$ GABA with the increasing concentration of $\mathrm{Tb}^{3+}: 0,30,100$, 300 , and $1000 \mu \mathrm{M}$. All recordings were obtained from the same neuron. $B$, The dose-response curve for $\mathrm{Tb}^{3+}$ potentiation of the current induced by $10 \mu \mathrm{M}$ GABA. The current amplitude is normalized to control current recorded in the absence of $\mathrm{Tb}^{3+}$. Data are given in the mean \pm SEM $(n=10)$ and fitted by Equation 1 with $K_{d}=356 \pm 12 \mu \mathrm{M}, h=1.91 \pm$ $0.4, I_{\max }=1055 \pm 97 \%$ of control, and $I_{\min }=123 \pm 15 \%$ of control. $C$, Shift of the dose-response curve for GABA-induced current by 100 $\mu \mathrm{M} \mathrm{Tb}^{3+}$ in the direction of low concentrations without changing the maximum response. The mean current amplitude with SEM $(n=6)$ is given as the percentage of current induced by $100 \mu \mathrm{M}$ GABA in the absence of $\mathrm{Tb}^{3+}$. Control data (open circles) are fitted by a curve calculated by Equation 1 with $K_{d}=25 \pm 0.5 \mu \mathrm{M}, h=1.78 \pm 0.3, I_{\max }=$ $109 \pm 0.3 \%$ of control, and $I_{\min }=1.18 \pm 0.5 \%$ of control. In the presence of $100 \mu \mathrm{M} \mathrm{Tb} \mathrm{Tb}^{3+}$, data (solid circles) arc fittcd by a curvc with $K_{d}=16$ $\pm 0.7 \mu \mathrm{M}, h=1.76 \pm 0.2, I_{\max }=112 \pm 3 \%$ of control, and $I_{\min }=2.98$ $\pm 1.8 \%$ of control.
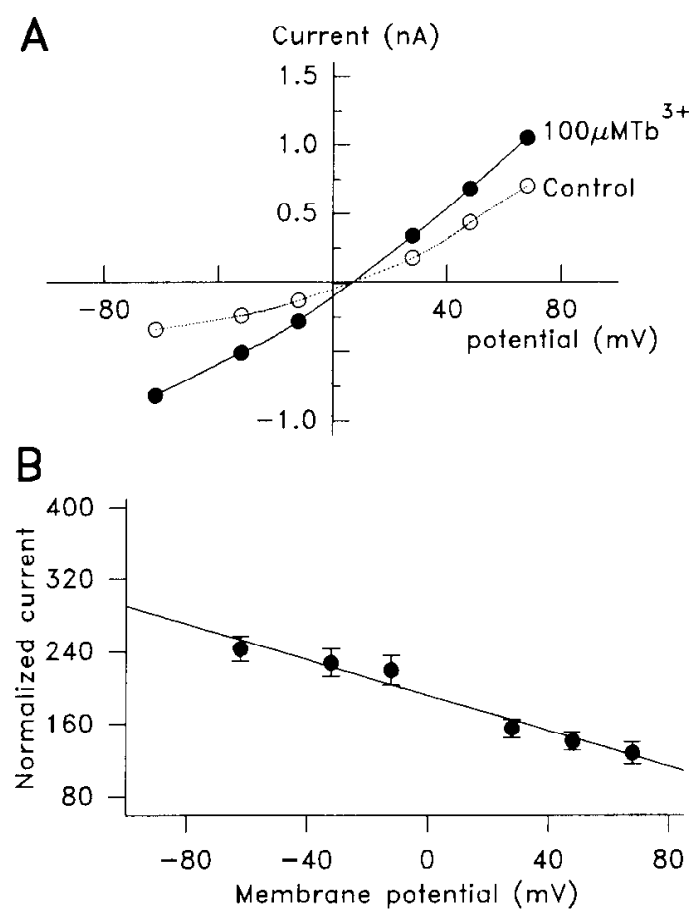

Figure 3. Terbium potentiation of GABA response is weakly voltage dependent. $A$, Current-voltage relationships for the current induced by $10 \mu \mathrm{M}$ GABA before (open circles) and during application of $100 \mu \mathrm{M}$ $\mathrm{Tb}^{3+}$ (solid circles). All data were obtained from the same neuron. $B$, The mean current amplitude with $\operatorname{SEM}(n=5)$ is given as the percentage of current induced by $10 \mu \mathrm{M}$ GABA in the absence of $100 \mu \mathrm{M} \mathrm{Tb}{ }^{3+}$ and plotted as a function of membrane potential. Line is drawn by a linear regression equation: $y-192-0.98 x$. The potentiation by $\mathrm{Tb}^{31} \mathrm{de}-$ creases $9.8 \%$ per $10 \mathrm{mV}$ depolarization.

following values were used to fit the data: $K_{d}=356 \pm 12 \mu \mathrm{M}$, $h=1.91 \pm 0.4, I_{\max }=1055 \pm 97 \%$ of control, and $I_{\min }=123$ $\pm 15 \%$ of control $(n=10)$. $\mathrm{Tb}^{3+}$ potentiation of GABA-induced current was dose dependent and the Hill coefficient was about 2. $\mathrm{Tb}^{3+}$ at a high concentration of $1 \mathrm{~mm}$ increased the GABAinduced current to 10 -fold of control. We have previously reported that $\mathrm{La}^{3+}$ potentiates the GABA-induced current from rat DRG neurons with $K_{d}=231 \pm 32 \mu \mathrm{M}$, a Hill coefficient of about 1 , and the maximal potentiation to about threefold of control (Yan and Narahashi, 1991). These results lead to two suggestions. First of all, although the efficacy for lanthanide enhancement varies among the different lanthanides, the potency of lanthanides remains at about the same level. In other words, the affinity of the GABA receptor-channel complex for the lanthanides is the same while the number of available binding sites for lanthanides increases with the decreasing atomic radii of the lanthanides. Second, the stoichiometry of lanthanide binding to a site is changed from $1: 1$ for $\mathrm{La}^{3+}$ to $2: 1$ for $\mathrm{Tb}^{3+}$. The binding of first $\mathrm{Tb}^{3+}$ ion may facilitate the binding of the second $\mathrm{Tb}^{3+}$ ion, resulting in the greater potentiation of GABA responses. More experiments will be needed to test these hypotheses.

In order to elucidate the mechanism by which $\mathrm{Tb}^{3+}$ augments the GABA-induced current, the dose-response curves for the GABA-induced current are compared in the presence and absence of $100 \mu \mathrm{M} \mathrm{Tb} b^{3+}$ (Fig. 2C). Under both conditions, the dose-response curves were fitted by the logistic function Equation 1 as described above. The $K_{d}$ for GABA in the absence of $\mathrm{Tb}^{3+}$ was estimated to be $25 \pm 0.5 \mu \mathrm{M}$, and the Hill coefficient, 
$1.78 \pm 0.3(n=6)$. The $K_{d}$ for GABA in the presence of 100 $\mu_{\mathrm{M}} \mathrm{Tb}^{3+}$ was decreased to $16 \pm 0.7 \mu \mathrm{M}$ and the Hill coefficient remained practically constant at $1.76 \pm 0.2(n=6)$. Thus, $\mathrm{Tb}^{3+}$ decreased the $K_{d}$ without changing the maximum response in a manner similar to $\mathrm{La}^{3+}$ potentiation of GABA response. The Hill coefficient was not altered significantly by $100 \mu \mathrm{M} \mathrm{Tb}^{3+}$. In summary, $\mathrm{Tb}^{3+}$ increased the affinity of GABA for the receptor without changing the number of active receptors.

\section{Terbium potentiation of $G A B A$ response is weakly voltage dependent}

To characterize the mechanism of $\mathrm{Tb}^{3+}$ potentiation of GABAinduced responses and to compare it with the actions of other modulators of GABA receptors, the voltage dependence of GABA-induced current was examined in the presence and absence of $100 \mu \mathrm{M} \mathrm{Tb} b^{3+}$ (Fig. 3). The current-voltage (I-V) curve, in the absence of $\mathrm{Tb}^{3+}$, showed some rectification in the negative potential region (Fig. $3 A$, open circles). The direction of the rectification is consistent with a decrease in the lifetime of opening of GABA-activated channels with membrane hyperpolarization (Onodera and Takeuchi, 1979). The reversal potential is slightly positive to $0 \mathrm{mV}(\sim+10 \mathrm{mV})$. The deviation of the reversal potential from $0 \mathrm{mV}$ in the presence of symmetrical chloride concentration inside and outside the cell is most likely due to different activity coefficients for chloride ions in the internal and external solutions, rather than incomplete equilibration of the cell interior with the pipette solution (Robertson, 1989). Maximum currents evoked by each test solution at holding potentials of $-60,-30,-10,+30,+50$, and $+70 \mathrm{mV}$ are plotted as a function of the holding potential (Fig. $3 B$ ). The $\mathrm{Tb}^{3+}$ potentiation of $\mathrm{GABA}$ responses became greater as the potential became more negative. There was a linear relationship between the augmentation of GABA-induced currents by $\mathrm{Tb}^{3+}$ and the membrane potential with a slope of $9.8 \%$ change per $10 \mathrm{mV}$. The data indicate that $\mathrm{Tb}^{3+}$ potentiation of GABA response is weakly voltage dependent. This observation is consistent with the voltage independence of $\mathrm{La}^{3+}$ potentiation (Ma and Narahashi, 1993).

\section{Lanthanide-induced inward currents}

In addition to potentiation of GABA-induced currents, lanthanides were found to produce inward currents by themselves at millimolar concentrations. Figure $4 A$ shows the currents recorded from the same neuron induced by $10 \mu \mathrm{M}$ GABA and various lanthanides ( $1 \mathrm{~mm}$ ), including $\mathrm{Lu}^{3+}, \mathrm{Er}^{3+}, \mathrm{Tb}^{3+}$, and $\mathrm{Ce}^{3+}$. The lanthanide-induced currents declined to the resting level upon removal of the test solutions from the bath in a manner similar to the GABA-induced currents. However, the lanthanide-induced currents were noisier and the onset and offset were often slower than those of GABA-induced currents. The amplitudes of lanthanide-induced currents as normalized to the amplitude of GABA-induced current were in following order (Fig. 4B): $\mathrm{Lu}^{3+} 101 \pm 8>\mathrm{Er}^{3+} 57 \pm 8>\mathrm{Tb}^{3+33 \pm 3}$ $>\mathrm{Eu}^{3+} 20 \pm 2>\mathrm{Nd}^{3+} 14 \pm 2 \approx \mathrm{Ce}^{3+} 13 \pm 0.6>\mathrm{La}^{3+} 10 \pm$ 0.2 . This rank order also correlates inversely with the hydrated ionic radii of lanthanides. The smaller the size of lanthanide molecule, the greater is the potentiation of GABA responses, and the larger is the inward current amplitude. These quantitative differences among various lanthanides should reflect some quantitative differences in the electronic configurations of these ions.

The $\mathrm{Tb}^{3+}$ was selected to study further the dose-response
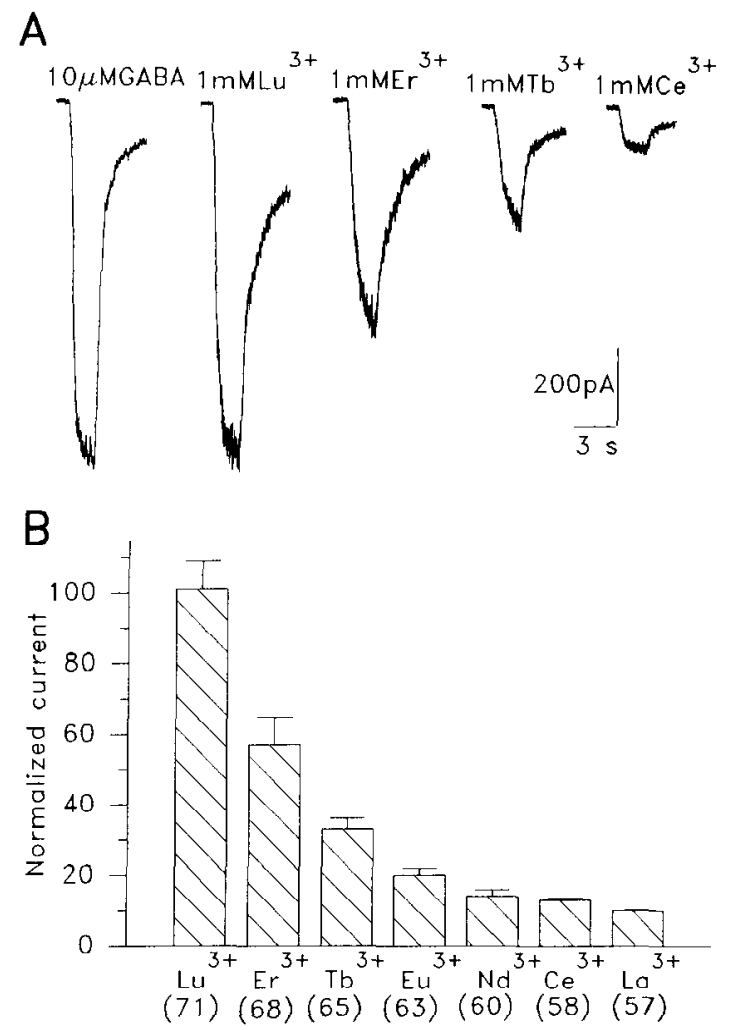

Figure 4. Lanthanides themselves generate inward currents. $A$, The responses to $1 \mathrm{mM} \mathrm{Lu}^{3+}, \mathrm{Er}^{3+}, \mathrm{Tb}^{3+}$, and $\mathrm{Ce}^{3+}$-induced currents at a holding potential of $-60 \mathrm{mV}$. All records were obtained from the same neuron. The current induced by $10 \mu \mathrm{M}$ GABA is shown for comparison. $B$, Summary of the data obtained in $A$. The ordinate represents the current amplitude with $\operatorname{SEM}(n=4)$ normalized to $10 \mu \mathrm{M}$ GABAinduced current. The numbers in parentheses are atomic numbers of lanthanides. The rank order correlates with the atomic numbers of lanthanides as well as the rank order of the efficacies for potentiation of GABA-induced current.

relationship of lanthanide-induced currents. For comparison, the dose-response relationship for the GABA-induced current was also studied. The current responses to the increasing concentrations of $\mathrm{Tb}^{3+}$ and GABA are shown in Figure 5, $A$ and $B . \mathrm{Tb}^{3+}$-induced currents were observed at concentrations higher than $100 \mu \mathbf{M}$ and no obvious desensitization occurred by concentrations up to $3 \mathrm{~mm}$. GABA-induced currents showed desensitization at a concentration of $30 \mu \mathrm{M}$ and above. The peak amplitudes of $\mathrm{Tb}^{3+}$ - and GABA-induced currents are plotted against the concentration of ${ }^{\prime} \mathrm{Ib}^{3+}$ and $\mathrm{GABA}$ in Figure $5, A$ and $B$, respectively. The dose-response curves were fitted by the logistic function Equation 1 as described above. The following values were used to fit the dose-response curve for $\mathrm{Tb}^{3+}: K_{d}=$ $863 \pm 0 \mu \mathrm{M}, h=2.19 \pm 0, I_{\max }=106.3 \pm 0 \%$ of control, and $I_{\text {min }}=2.61 \pm 0 \%$ of control $(n=5)$. Thus, currents induced by $\mathrm{Tb}^{3+}$ were dose dependent. The stoichiometry of $\mathrm{Tb}^{3+}$ binding to a site is $2: 1$ as in the case of GABA. For the GABA doseresponse curve, values used to fit the solid curve were $K_{d}=25$ $\pm 0.5 \mu \mathrm{M}, h=1.78 \pm 0.3, I_{\max }=109.3 \pm 0.3 \%$ of control, and $I_{\min }=1.18 \pm 0.5 \%$ of control $(n=6)$. To compare the doseresponse curves for $\mathrm{Tb}^{3+}$ and $\mathrm{GABA}$ directly, the amplitudes of the $\mathrm{Tb}^{3+}$-induced currents were normalized to those of the GABA-induced currents and are replotted in Figure $5 B$. Both the potency and efficacy of $\mathrm{Tb}^{3+}$ to produce an inward current are much smaller than those of GABA. 
A

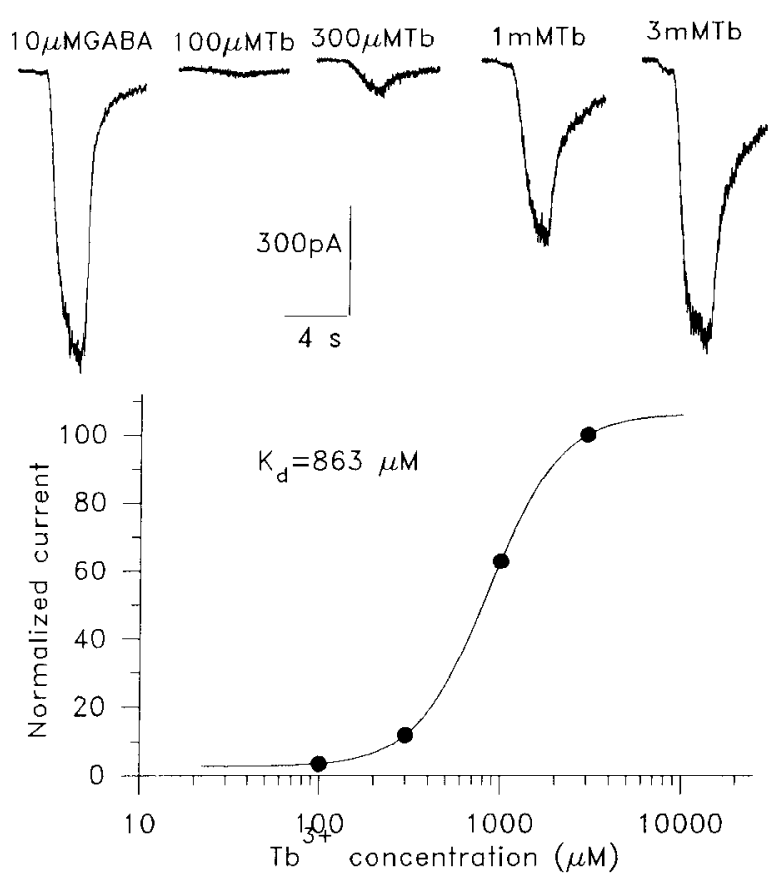

B

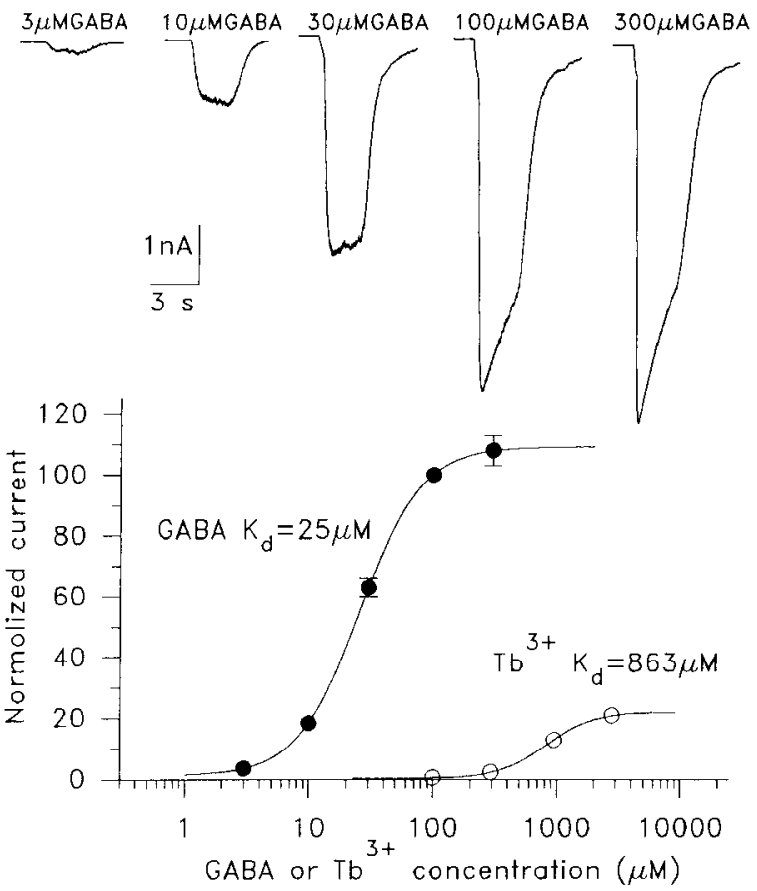

Figure 5. Dose-response relationships for $\mathrm{Tb}^{3+}$ - and GABA-induced currents. $A$, The current responses to the increasing concentration of $\mathrm{Tb}^{3+}$ : $100,300,1000$, and $3000 \mu \mathrm{M}$. The current induced by $10 \mu \mathrm{M}$ GABA is shown for comparison. All records were obtained from the same neuron. The dose-response curve for $\mathrm{Tb}^{3+}$-induced currents is shown in the lower panel. The mean current amplitude with SEM $(n=5)$ is given as the percentage of current induced by $3 \mathrm{mM} \mathrm{Tb}^{3+}$. Data are fitted by Equation 1 with $K_{d}=863 \pm 0 \mu \mathrm{M}, h=2.19 \pm 0, I_{\max }=106 \pm 0 \%$ of control, and $I_{\min }=2.16 \pm 0 \%$ of control. $B$, The current responses to the increasing concentration of GABA: $3,10,30,100$, and $300 \mu \mathrm{M}$. GABA induced current desensitizes at concentrations above $30 \mu \mathrm{M}$. All records were obtained from the same neuron. Comparison of the dose-response curves for GABA and $\mathrm{Tb}^{3+}$ (data from $\left.A\right)$ is shown in the lower panel. The mean current amplitude with SEM $(n=6)$ is given as the percentage of current induced by $100 \mu \mathrm{M} \mathrm{GABA}$. Data for GABA (solid circles) are fitted by Equation 1 with $K_{d}=25 \pm 0.5 \mu \mathrm{M}, h=1.78 \pm 0.3, I_{\max }=109 \pm 0.3 \%$ of control, and $I_{\min }=1.18 \pm 0.5 \%$ of control. For data for $\mathrm{Tb}^{3+}$ (open circles), the parameters are the same as those of $A$. Note the different current calibrations between $A$ and $B$.

\section{Potentiation of $T b^{3+}$ response by pentobarbital and chlordiazepoxide}

The $\mathrm{GABA}_{\mathrm{A}}$ receptor-channel complex has been established as a multimeric receptor protein with an integral chloride ion channel and some allosteric binding sites for drugs such as benzodiazepines, barbiturates, and PTX (Barnard et al., 1987; Bormann et al., 1987). GABA-induced chloride currents are allosterically potentiated by several drugs such as $\mathrm{PB}$ and CDPX. If $\mathrm{Tb}^{3+}$ acts as an agonist on the GABA site to open the GABAgated chloride channel, then $\mathrm{Tb}^{31}$-induced currents should be enhanced by both PB and CDPX. This was actually the case. $\mathrm{PB}$ at $100 \mu \mathrm{M}$ potentiated the $1 \mathrm{mM} \mathrm{Tb}^{3+}$-induced current to 6.8-fold of control and by itself produced a small inward current (Fig. 6A). CDPX at $50 \mu \mathrm{M}$ potentiated $1 \mathrm{~mm} \mathrm{~Tb}^{3+- \text {-induced }}$ current to 2.0-fold of control (Fig. 6B). PB and CDPX at $1 \mathrm{~mm}$ also potentiated the GABA responses from rat DRG neurons to about seven- and twofold of control, respectively (Ma and Narahashi, 1993). Therefore, PB and CDPX potentiate both GABA- and $\mathrm{Tb}^{3+}$-induced currents to the same degree.

\section{$T b^{3+}-$ induced currents reversed at chloride equilibrium potential}

Several metals have been reported to produce slow inward, nonselective cation currents, including $\mathrm{Ca}^{2+}$ (Yellen, 1982; Partridge and Swandulla, 1988), $\mathrm{Cd}^{2+}, \mathrm{Pb}^{2+}$, and $\mathrm{Al}^{3+}$ (Oortgiesen et al., 1990), and $\mathrm{Hg}^{2+}$ (Arakawa et al., 1991). To determine the ionic nature of the lanthanide-induced currents, $I-V$ curves for both $10 \mu \mathrm{M}$ GABA and $1 \mathrm{mM} \mathrm{Tb}^{3+}$ obtained from the same neuron are plotted in Figure $6 \mathrm{C}$. In the presence of symmetrical chloride concentration inside and outside the cell, currents induced by both $10 \mu \mathrm{M}$ GABA and $1 \mathrm{mM} \mathrm{Tb}^{3+}$ reversed at about $+10 \mathrm{mV}$. $I-V$ curve for $\mathrm{Tb}^{3+}$ showed some rectification in the negative potential region as $I-V$ curves did for GABA. Similar results were obtained from four other neurons. This indicates that $\mathrm{Tb}^{3+}$-induced currents are carried by chloride and $\mathrm{Tb}^{3+}$ may open the same chloride channels as GABA does.

Block of $T b^{3+}$-induced currents by GABA antagonists

Pharmacological characteristics of $\mathrm{Tb}^{3+}$-induced currents were also examined using several drugs known to exert specific blocking effects on GABA receptor-channel complex, that is, bicuculline, PTX, penicillin, and $\mathrm{Zn}^{2+}$. All of the four antagonists suppressed both GABA- and $\mathrm{Tb}^{3+}$-induced currents reversibly (data not shown). The sensitivity of both GABA- and $\mathrm{Tb}^{3+}$ induced currents to the four GABA response antagonists is summarized in Figure 7. Bicuculline is a specific antagonist for GABA site and at $10 \mu \mathrm{M}$ reduced $10 \mu \mathrm{M} \mathrm{GABA}$-induced currents to 25 $\pm 3 \%$ of control $(n=4) . \mathrm{Tb}^{3+}(1 \mathrm{mM})$-induced currents were also reduced to $24 \pm 2 \%$ of control by $10 \mu \mathrm{M}$ bicuculline ( $n=$ 4). Thus, bicuculline almost equally blocks both GABA- and $\mathrm{Tb}^{3+}$-induced currents. This suggests that $\mathrm{Tb}^{3+}$ acts on the GABA 
A
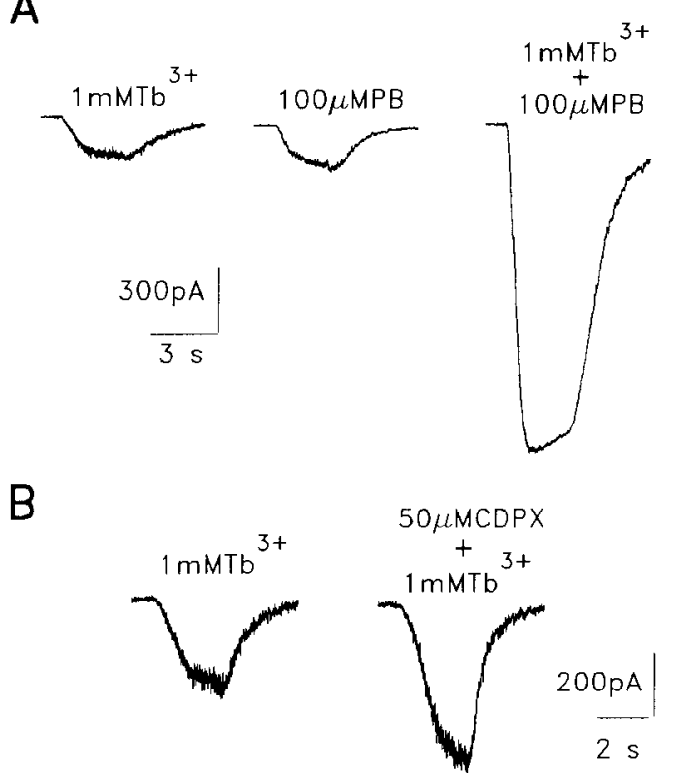

C

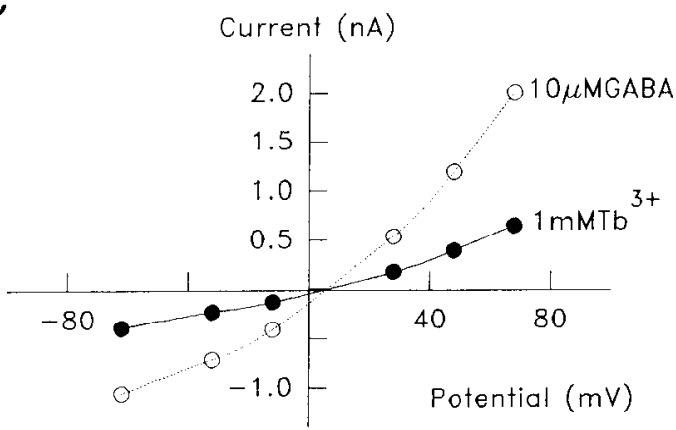

Figure 6. $\mathrm{Tb}^{3+}$-induced currents are potentiated by PB and CDPX. $A$, Potentiation of $\mathrm{Tb}^{3+}$-induced currents by PB. PB $(100 \mu \mathrm{M})$ increases the $\mathrm{Tb}^{3+}$-induced current to 6.8 times that of control. $B$, Potentiation of $\mathrm{Tb}^{3+}$-induced currents by CDPX. CDPX $(50 \mu \mathrm{M})$ increases the $\mathrm{Tb}^{3+}$ induced current to 2.0 times that of control. $C$, Both GABA- and $\mathrm{Tb}^{3+}$ induced currents are reversed at the chloride equilibrium potential $(\sim+10$ $\mathrm{mV}$ ). At holding potentials ranging from $-60 \mathrm{mV}$ to $+70 \mathrm{mV}$, the inward rectification associated with $10 \mu \mathrm{M}$ GABA-induced currents at negative potentials is also seen with $1 \mathrm{~mm} \mathrm{~Tb}^{3+}$-induced current. The deviations of the reversal potential from $0 \mathrm{mV}$ for both GABA and $\mathrm{Tb}^{3+}$ responses are most likely due to different activity coefficients for chloride ions in the internal and external solutions, suggesting that $\mathrm{Tb}^{3+}$ opens the same chloride channel as does GABA. All data were obtained from the same neuron.

site to open the chloride channel since bicuculline is a competitive inhibitor for GABA binding site. PTX is an allosteric antagonist and at $10 \mu \mathrm{M}$ reduced $10 \mu \mathrm{M}$ GABA-induced currents to $24+3 \%$ of control $(n=3)$. However, $1 \mathrm{mM} \mathrm{Tb}^{3+}$-induced currents were reduced to only $72 \pm 4 \%$ of control by $10 \mu \mathrm{M}$ PTX $(n=4)$. The GABA-induced currents are more sensitive to PTX than the $\mathrm{Tb}^{3+}$-induced currents. Penicillin has recently been shown to be a chloride channel blocker (Twyman et al., 1992). Penicillin at $500 \mu \mathrm{M}$ reduced $10 \mu \mathrm{M}$ GABA-induced currents to $25 \pm 5 \%$ of control $(n=4)$, and reduced $1 \mathrm{mM} \mathrm{Tb}^{3+}$ induced currents to $84 \pm 3 \%$ of control $(n=3)$. As in the case of PTX, penicillin blocked GABA response more effectively than $\mathrm{Tb}^{3+}$ response. $\mathrm{Zn}^{2+}$ is an allosteric blocker and at $20 \mu \mathrm{M}$ reduced $10 \mu \mathrm{M}$ GABA-induced currents to $53 \pm 2 \%$ of control $(n=3)$. $\mathrm{Tb}^{3+}$-induced currents were suppressed by $20 \mu \mathrm{M} \mathrm{Zn}^{2+}$ only to

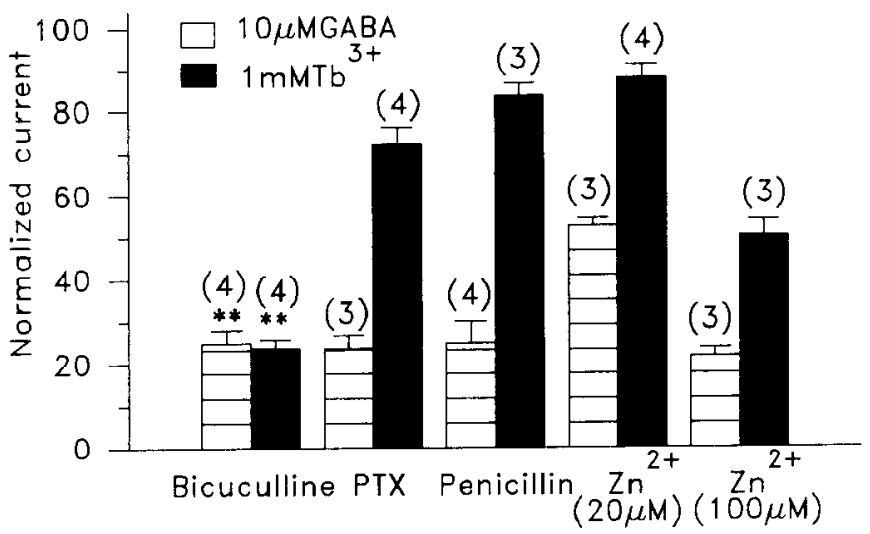

Figure 7. PTX, penicillin, and $\mathrm{Zn}^{2+}$ all block the currents induced by GABA more effectively than those induced by of $\mathrm{Tb}^{3+}$. Bicuculline blocks the both currents equally. The ordinate represents the mean amplitude with SEM of GABA- and $\mathrm{Tb}^{3+}$-induced currents in the presence of blockers as the percentage of the respective control currents without blockers. Bicuculline $(10 \mu \mathrm{M})$ reduces both $\mathrm{GABA}-$ and $\mathrm{Tb}^{3+}$. induced currents equally, to $25 \%$ and $24 \%$ of control, respectively. PTX $(10 \mu \mathrm{M})$ reduces GABA-induced currents more effectively than $\mathrm{Th}^{3+}$ induced currents, to $24 \%$ and $72 \%$ of control, respectively. Penicillin $(500 \mu \mathrm{M})$ reduces GABA-induced currents more effectively than $\mathrm{Tb}^{3+}$. induced currents, to $25 \%$ and $84 \%$ of control, respectively. $\mathrm{Zn}^{2+}$ at both $20 \mu \mathrm{M}$ and $100 \mu \mathrm{M}$ reduces GABA responses more effective than $\mathrm{Tb}^{3+}$ responses: $\mathrm{Zn}^{2+}$ at $20 \mu \mathrm{M}$ reduces the current to $53 \%$ and $88 \%$ of control, respectively; $\mathrm{Zn}^{2+}$ at $100 \mu \mathrm{M}$ reduced the current to $22 \%$ and $52 \%$ of control, respectively. Numbers of cells examined are shown in parentheses. Asterisks indicate those two bars are not statistically different from each other.

$88 \pm 3 \%$ of control $(n=4)$. When the $\mathrm{Zn}^{2+}$ concentration was

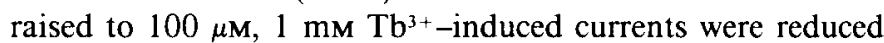
to $52 \pm 4 \%$ of control $(n=3)$ while $10 \mu \mathrm{M}$ GABA-induced currents were reduced to $22 \pm 2 \%$ of control $(n=3)$. It is clear that $\mathrm{Tb}^{3+}$-induced currents are inhibited by all the four blockers: PTX, penicillin, and $\mathrm{Zn}^{2+}$ have less effects on $\mathrm{Tb}^{3+}$-induced currents than on GABA-induced currents, whereas bicuculline has the equal effect on both currents.

\section{Discussion}

The present study has clearly demonstrated that lanthanides augment the GABA-induced chloride currents as much as 10 fold of control in rat DRG neurons. This modulation occurs with fast onset and offset and is weakly voltage dependent. The efficacy of lanthanides to potentiate GABA response correlates inversely with the atomic radii of these ions: the smaller the radius, the greater is the potentiation. In addition to potentiation, lanthanides also produce inward currents reversibly in rat DRG neurons.

\section{Enhancement of GABA-induced chloride currents by lanthanides}

All the lanthanides tested potentiate the GABA-induced currents at $1 \mathrm{~mm}$ concentration, with $\mathrm{Lu}^{3+}$ having the greatest efficacy and $\mathrm{La}^{3+}$ the least efficacy. $\mathrm{Tb}^{3+}$ increases the GABAinduced currents in a dose-dependent manner, with an apparent $K_{d}$ of $356 \mu \mathrm{M}$ and the maximum increase to about 10 -fold of control. Reichling and MacDermott (1991) reported that the $\mathrm{La}^{3+}$ effect on GABA response of rat dorsal horn neurons was biphasic: at concentrations between 1 and $100 \mu \mathrm{M}$ the effect was predominantly enhancement with the maximum increase to about $130 \%$ of control, whereas at higher concentrations the 
GABA response was reduced dramatically. In our experiments no such suppression was ever seen at a concentration of $1 \mathrm{~mm}$ of any of the lanthanides tested. The reason for this discrepancy remains to be seen. One possible explanation is that the difference may reflect the heterogeneity of $\mathrm{GABA}_{\mathrm{A}}$ receptors expressed in the two preparations. In fact, $\gamma$-subunit of $\mathrm{GABA}_{\mathrm{A}}$ receptors has been recently shown to be important for lanthanum potentiation of GABA responses (Im et al., 1992).

There are several possible explanations for the potentiating effects of lanthanides. First of all, the effect of lanthanides could be a $\mathrm{Ca}^{2+}$-mediated event since lanthanides are considered as antagonists of or substitutes for calcium in a variety of cellular reactions and have been employed extensively in studies of metal-protein interaction, membrane structure, and particularly the calcium pathway (Martin and Richardson, 1979; Sun and Petersheim, 1990; Ogurusu et al., 1991; Tellam, 1991). Lanthanides could increase (as substitutes) or decrease (as antagonists) the effective concentration of extracellular $\mathrm{Ca}^{2+}$, thereby affecting the GABA response. However, changing the extracellular concentration of $\mathrm{Ca}^{2+}$ has no effect on GABA-induced responses (Kaneko and Tachibana, 1986; Celentano et al., 1991). All types of $\mathrm{Ca}^{2+}$ channels are closed at a membrane potential of -60 or $-70 \mathrm{mV}$ and no voltage-activated $\mathrm{Ca}^{2+}$ channels should be involved. Second, nonspecific screening of negative charges on the membrane surface by cations could increase the binding of negatively charged molecules to the membrane (MaLaughlin et al., 1971; Mozhayeva and Naumov, 1972; Vogel, 1974; Ohmori and Yoshii, 1977), thereby increasing the effective concentration of GABA on the membrane surface. However, this explanation seems unlikely because other divalent cations cither have no effects (such as $\mathrm{Mn}^{2+}$ ) or decrease the GABA responses (such as $\mathrm{Zn}^{2+}$ ). Finally, our data are consistent with the possibility that lanthanides bind to an extracellular site on the GABA receptor-channel complex and increase the affinity of GABA for its binding site through allosteric interaction. Lanthanides can hardly penetrate the cell membrane to any significant degree (Lesseps, 1967; Langer and Frank, 1972), and the enhancement of GABA response by lanthanides occurs with fast onset and offset, in support of the direct action on an extracellular site(s). We have previously shown that $\mathrm{La}^{3+}$ does not interact with any of the benzodiazepine, barbiturate, and PTX binding sites on the GABA receptor-channel complex (Yan and Narahashi, 1992). Based on the similarity in action among the various lanthanides, it is reasonable to assume that this $\mathrm{La}^{3+}$ site is shared by all the lanthanides tested. The luminescence study reveals that the lanthanide binding site on protcins is in close proximity to an aromatic acid(s), particularly an aromatic chain of tryptophan, tyrosine, and phenylalanine (Martin and Richardson, 1979). This information may be useful in determining the location of lanthanide binding domains in GABA receptor-channel complex.

Electronic configurations of different lanthanides may be related to the differences in efficacy in potentiating GABA responses. Electrons are progressively added to the $4 f$ subshell from $\mathrm{La}^{3+}$ to $\mathrm{Lu}^{3+}$. The addition of electrons into the inner subshells increases the binding energy of the valence electrons. As a result, the ionic radii of the lanthanides decrease as their atomic numbers increase, a paradox known as the "lanthanide contraction" (Evans, 1983). We have shown in the present study that although the potencies of $\mathrm{La}^{3+}$ and $\mathrm{Tb}^{3+}$ to potentiate the GABA response are about the same, the maximal potentiation by $\mathrm{Tb}^{3+}$ was much larger than that by $\mathrm{La}^{3+}$. This suggests that the GABA receptor-channel complex binds more $\mathrm{Tb}^{3+}$ ions than $\mathrm{La}^{3+}$ ions, possibly due to the smaller size of $\mathrm{Tb}^{3+}$ than $\mathrm{La}^{3+}$ as a result of the lanthanide contraction. Thus, $\mathrm{Tb}^{3+}$ has the higher surface charge density than $\mathrm{La}^{3+}$ and by some unknown mechanisms produces a larger potentiation. This is consistent with the observation that one GABA receptor-channel complex can bind two $\mathrm{Tb}^{3+}$ ions but only one $\mathrm{La}^{3+}$ ion. In addition, chemical differences between the different members of the lanthanide series tend to be quantitative rather than qualitative. The differences in efficacy for lanthanide potentiation of GABA responses reflect the quantitative chemical differences among the lanthanide members.

\section{Generation of inward chloride currents by lanthanides}

All the lanthanides tested producc inward currents at $1 \mathrm{~mm}$ concentration, with $\mathrm{Lu}^{3+}$ inducing the largest and $\mathrm{La}^{3+}$ inducing the smallest currents. The order of efficacies to produce the currents correlates with the atomic numbers of these ions. The lanthanide-induced currents are subject to the modulation by all the GABA receptor-channel complex reagents tested, that is, $\mathrm{PB}, \mathrm{CDPX}, \mathrm{PTX}$, and $\mathrm{Zn}^{2+}$. Similar results were obtained with barbiturates. Barbiturates greally enhance the GABA-induced currents at low concentrations and generate inward chloride currents at high concentrations (Nicoll, 1975; Barker and Ransom, 1978; Akaike et al., 1985). Interestingly, PB-induced currents are also blocked by bicuculline and PTX (Nicoll and Wojtowicz, 1980). The stoichiometry of GABA, $\mathrm{Tb}^{3+}$, and $\mathrm{PB}$ binding to a site is the same at $2: 1$. A question then arises as to whether GABA, lanthanides, and barbiturates share the same GABA binding site to induce inward currents. The results from

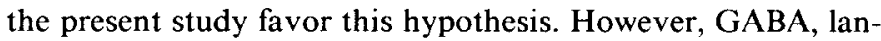
thanides, and PB are structurally different and PB fails to displace GABA from specific binding sites (Olsen et al., 1977; Peck et al., 1978). The GABA- and $\mathrm{Tb}^{3+}$-induced currents showed different sensitivities to different $\mathrm{GABA}$ receptor antagonists in the present study. Thus, the detailed mechanisms of direct action of these chemicals on the GABA system remain to be seen. Since the lanthanides are useful luminescence probes to investigate the metal-protein interactions, they have a distinct advantage for the study of binding mechanism. It appears that lanthanides bind to two sites: a site different from any of the GABA, barbiturate, benzodiazepine, PTX, and $\mathrm{Cu}^{2+} / \mathrm{Zn}^{2+}$ sites for potentiation of GABA response, and the GABA binding site to generate chloride currents.

\section{References}

Akaike N, Hattori K, Inomata N, Oomura Y (1985) $\gamma$-Aminobutyricacid- and pentobarbitone-gated chloride currents in internally perfused frog sensory neurones. J Physiol (Lond) 360:367-386.

Anghileri AJ, Crone-Escanye M, Bobert J (1987) Anticancer activity of gallium and lanthanum: role of cation-cell membrane interaction. Anticancer Res 7:1205-1208.

Arakawa O, Nakahiro M, Narahashi T (1991) Mercury modulation of GABA-activated chloride channels and non-specific cation channels in rat dorsal root ganglion neurons. Brain Res 551:58-63.

Barker JL, Ransom BR (1978) Pentobarbitone pharmacology of mammalian central neurones grown in tissue culture. J Physiol (Lond) 280: 355-372.

Barnard EA, Darlison MG, Seeburg P (1987) Molecular biology of the GABA receptor: the receptor/channel superfamily. Trends Neurosci 10:502-509.

Bormann J, Hamill OP, Sakmann B (1987) Mechanism of anion permeation through channels gated by glycine and $\gamma$-aminobutyric acid in mouse cultured spinal neurones. J Physiol (Lond) 385:243-286.

Canada RG, Carpenter RG (1991) Physicochemical characteristics of 
the terbium-adriamycin complex and its effects on the sinus node automaticity. Biochim Biophys Acta 1073:136-141.

Celentano JJ, Gyenes M, Gibbs TT, Farb DH (1991) Negative modulation of the $\gamma$-aminobutyric acid responses by extracellular zinc. Mol Pharmacol 40:766-773.

Das T, Sharma A, Talukder G (1988) Effects of lanthanum in cellular systems. Biol Trace Elem Res 18:201-228.

Evans $\mathrm{CH}$ (1983) Interesting and useful biochemical properties and lanthanides. Trends Biochem Sci 8:445-449.

Fenwick EM, Marty A, Neher E (1982) A patch-clamp study of bovine chromaffin cells and of their sensitivity to acetylcholine. J Physiol (Lond) 331:577-597.

Haley JT (1965) Pharmacology and toxicology of the rare earth elements. J Pharm Sci 54:663-670.

Hamill OP, Marth A, Neher E, Sakmann B, Sigworth FJ (1981) Improved patch-clamp techniques for high-resolution current recording from cells and cell-free membrane patches. Pfluegers Arch 391:85100.

Im MS, Hamilton BJ, Carter DB, Im WB (1992) Selective potentiation of GABA-mediated $\mathrm{Cl}^{-}$current by lanthanum ion in subtypes of cloned GABA Aeceptors. Neurosci Lett 144:165-168.

Kaneko A, Tachibana M (1986) Blocking effects of cobalt and related ions on the $\gamma$-aminobutyric acid-induced current in turtle retinal cones. J Physiol (Lond) 373:463-479.

Langer GA, Frank JS (1972) Lanthanum in heart cell culture. Effect of calcium exchange correlated with its localization. J Cell Biol 54: $441-445$.

Lesseps RJ (1967) Removal by phospholipase C of a layer of $\mathrm{La}$ staining material external to the cell membrane in embryonic chick cells. J Cell Biol 34:173-183.

Ma JY, Narahashi T (1993) Differential modulation of $\mathrm{GABA}_{\mathrm{A}}$ receptor-channel complex by polyvalent cations in rat dorsal root ganglion neurons. Brain Res 607:222-232.

MaLaughlin S, Szabo G, Eisenman G (1971) Divalent ions and the surface potential of charged phospholipid membranes. J Physiol (Lond) 58:667-687.

Martin RB, Richardson FS (1979) Lanthanides as probes for calcium in biological systems. Q Rev Biophys 12:181-209.

Mozhayeva GN, Naumov AP (1972) Tetraethylammonium ion inhibition of potassium conductance of the nodal membrane. Biochim Biophys Acta 290:248-255.

Nicoll RA (1975) Presynaptic action of barbiturates in the frog spinal cord. Proc Natl Acad Sci USA 72:1460-1462.

Nicoll RA, Wojtowicz JM (1980) The effects of pentobarbital and related compounds on frog motoneurons. Brain Res 191:225-237.

Ogurusu T, Wakabayashi S, Shigekawa M (1991) Functional characterization of lanthanide binding sites in the sarcoplasmic reticulum $\mathrm{Ca}^{2+}$-ATPase: do lanthanide ions bind to the calcium transport site? Biochemistry 30:9966-9973.

Ohmori H, Yoshii M (1977) Surface potential reflected in both gating and permeation mechanism of sodium and calcium channels of the tunicate egg cell membrane. J Physiol (Lond) 267:429-463.

Olsen RW, Lamar EE, Bayless JO (1977) Calcium-induced release of $\gamma$-aminobutyric acid from synaptosomes: effect of tranquilizer drugs. J Neurochem 28:299-305.

Onodera K, Takeuchi A (1979) An analysis of the inhibitory postsynaptic current in the voltage-clamped crayfish muscle. J Physio (Lond) 286:265-282.

Oortgiesen M, van Kleef RGDM, Vijverberg HPM (1990) Novel type of ion channel activated by $\mathrm{Pb}^{2+}, \mathrm{Cd}^{2+}$, and $\mathrm{Al}^{3+}$ in cultured mouse neuroblastoma cells. J Membr Biol 113:261-268.

Peck EJ, Miller AL, Leser BB (1978) Pentobarbital and synaptic highaffinity receptor sites for gamma-aminobutyric acid. Brain Res Bull 1:595-597.

Partridge LD, Swandulla D (1988) Calcium-activated non-specific cation channels. Trends Neurosci 11:69-72.

Reichling DB, MacDermott AB (1991) Lanthanum actions on excitatory amino acid-gated currents and voltage-gated calcium currents in rat dorsal horn neurons. J Physiol (Lond) 441:199-218.

Robertson B (1989) Characteristic of GABA-activated chloride channels in mammalian dorsal root ganglion neurons. J Physiol (Lond) 144:285-300.

Sedmak JJ, MacDonald HS, Kushnaryov VM (1986) Lanthanide ion enhancement of interferon binding to cells. Biochem Biophys Res Commun 137:480 -485 .

Shannon RD (1976) Revised effective ionic radii and systematic studies of interatomic distances in halides and chalcogenides. Acta Crystallogr A32:751-767.

Smart TG (1992) A novel modulatory binding site for zinc on the $\mathrm{GABA}_{\mathrm{A}}$ receptor complex in cultured rat neurones. J Physiol (Lond) 447:587-625.

Sun J, Petersheim M (1990) Lanthanide(III)-phosphatidic acid complexes: binding site heterogeneity and phase separation. Biochim Biophys Acta 1024:159-166.

Tellam RL (1991) The binding of terbium ions to gelsolin reveals two classes of metal ion binding sites. Arch Biochem Biophys 288:185191.

Twyman RE, Green RM, Macdonald RL (1992) Kinetics of open channel block by penicillin of single GABA $_{\mathrm{A}}$ receptor channels from mouse spinal cord neurones in culture. J Physiol (Lond) 445:97-127.

Vardimon AD, Graber TM, Drescher D, Bourauel C (1991) Rare earth magnets and impaction. Am J Orthod Dentofacial Orthop 100:494512.

Venugopal B, Luckey TD (1978) Toxicity of group III metals. In: Metal toxicity in mammals, pp 127-157. New York: Plenum.

Vogel W (1974) Calcium and lanthanum effects at the nodal membrane. Pfluegers Arch 350:25-39.

Yamage M, Evans CH (1989) Suppression of mitogen- and antigeninduced lymphocyte proliferation by lanthanides. Experientia 45:1 1291131 .

Yan M, Narahashi T (1991) Differential modulation of GABA receptor channel by polyvalent cations. Soc Neurosci Abstr 17:1333.

Yan M, Narahashi T (1992) Modulation of GABA receptor-channel complex by polyvalent cations. Biophys J 62:A105.

Yellen $\mathrm{G}$ (1982) Single $\mathrm{Ca}^{2+}$-activated nonselective cation channels in neuroblastoma. Nature 296:357-359. 